\title{
Fumarate modulates the immune/ inflammatory response and rescues nerve cells and neurological function after stroke in rats
}

Ruihe Lin ${ }^{1}$, Jingli Cai ${ }^{1}$, Eric W. Kostuk ${ }^{1}$, Robert Rosenwasser ${ }^{2}$ and Lorraine lacovitti ${ }^{1 *}$ (i)

\begin{abstract}
Background: Dimethyl fumarate (DMF), working via its metabolite monomethylfumarate (MMF), acts as a potent antioxidant and immunomodulator in animal models of neurologic disease and in patients with multiple sclerosis. These properties and their translational potential led us to investigate whether DMF/MMF could also protect at-risk and/or dying neurons in models of ischemic stroke in vitro and in vivo. Although the antioxidant effects have been partially addressed, the benefits of DMF immunomodulation after ischemic stroke still need to be explored.
\end{abstract}

Methods: In vitro neuronal culture with oxygen-glucose deprivation and rats with middle cerebral artery occlusion were subjected to DMF/MMF treatment. Live/dead cell counting and LDH assay, as well as behavioral deficits, plasma cytokine assay, western blots, real-time PCR (Q-PCR) and immunofluorescence staining, were used to evaluate the mechanisms and neurological outcomes.

Results: We found that MMF significantly rescued cortical neurons from oxygen-glucose deprivation (OGD) in culture and suppressed pro-inflammatory cytokines produced by primary mixed neuron/glia cultures subjected to OGD. In rats, DMF treatment significantly decreased infarction volume by nearly $40 \%$ and significantly improved neurobehavioral deficits after middle cerebral artery occlusion (MCAO). In the acute early phase (72 $\mathrm{h}$ after MCAO), DMF induced the expression of transcription factor Nrf2 and its downstream mediator HO-1, important for the protection of infarcted cells against oxidative stress. In addition to its antioxidant role, DMF also acted as a potent immunomodulator, reducing the infiltration of neutrophils and T cells and the number of activated microglia/ macrophages in the infarct region by more than $50 \%$ by 7-14 days after MCAO. Concomitantly, the levels of potentially harmful pro-inflammatory cytokines were greatly reduced in the plasma and brain and in OGD neuron/ glia cultures.

Conclusions: We conclude that DMF is neuroprotective in experimental stroke because of its potent immunomodulatory and antioxidant effects and thus may be useful as a novel therapeutic agent to treat stroke in patients.

Keywords: Stroke, Inflammation, Dimethyl fumarate

\footnotetext{
* Correspondence: Lorraine.iacovitti@jefferson.edu

${ }^{1}$ The Joseph and Marie Field Cerebrovascular Research Laboratory at

Jefferson, Vickie \& Jack Farber Institute for Neurosciences, Department of

Neuroscience, Sidney Kimmel Medical College, Thomas Jefferson University,

900 Walnut Street, Philadelphia, PA 19107, USA

Full list of author information is available at the end of the article
} 


\section{Background}

In ischemic stroke, which is the leading cause of disability and the second leading cause of death worldwide [1], neuronal destruction is caused both by oxygen deprivation $[2,3]$ and by persistent activation of the host immune system [4-32]. After vessel occlusion, the loss of neurons occurs chiefly from the lack of oxygen supply and concomitant oxidative stress in the ischemic core. However, neuronal death in the surrounding penumbra area subsequently develops in large part from inflammation due to the infiltration of immune cells and the release of destructive cytokines. Thus, a novel regimen which enhances both cellular resistance to oxidative stress and modulation of the immune response could provide greater neuroprotection after ischemic stroke.

Intriguingly, the methyl ester of fumaric acid, dimethyl fumarate (DMF), working via its metabolite monomethylfumarate (MMF), acts as both a potent immunomodulator and antioxidant in laboratory models of disease [33-41] and in patients with neurological disease like multiple sclerosis (MS) [42, 43]. Moreover, several recent reports showed that DMF can also reduce brain edema and improve blood-brain barrier (BBB) integrity and improve neurological outcomes in a short-term rat model of hemorrhagic stroke $[40,44]$ and ischemic stroke $[45,46]$. In all of these cases, DMF/MMF is thought to act via activation of the antioxidant transcription factor (erythroid-derived 2)-like 2 (Nrf2) which up-regulates proteins like heme oxygenase-1 (HO-1) [33, 36-38, 40, 41, $44,47]$, thereby protecting cells against damage triggered by oxidant insult. Additionally, DMF is a potent modulator of inflammatory cytokines which are now known as important in stroke [11, 15, 20-22, 26, 27, 48, 49], in particular Th1-type pro-inflammatory cytokines that can lead to tissue damage $[37,38,40,50,51]$.

Because of its acute antioxidant and prolonged immunomodulatory mechanisms of action and its translational potential in humans, we wondered whether DMF/MMF could protect both dying neurons in the ischemic core as well as neurons at-risk of dying at later times after stroke. We show here that MMF is neuroprotective to cortical neurons after oxygen-glucose deprivation (OGD) in a model of stroke in culture. In addition, in a rat model of experimental stroke, DMF significantly decreased infarction volume and improved neurobehavioral deficits 14 days after middle cerebral artery occlusion (MCAO), concomitant with the induction of $\mathrm{Nrf} 2$ and HO-1 and the reduction in immune cell infiltration and harmful inflammatory cytokines in the plasma and brain.

\section{Methods}

\section{Animals}

All procedures in this study were carried out in accordance with the recommendations in the Guide for the
Care and Use of Laboratory Animals of the National Institutes of Health. The protocol was approved by the IACUC Committee of Thomas Jefferson University.

\section{Antibodies and reagents}

Dimethyl fumarate (DMF) and mono-methyl fumarate (MMF) were purchased from Sigma-Aldrich. Poly-D-lysine, DMSO and Glutamax were purchased from Sigma. HBSS, DMEM, fetal calf serum, Neurobasal medium, B27 supplement were purchased from Invitrogen. LIVE/ DEAD viability/cytotoxicity kit was purchased from Molecular Probes. The cytotoxicity detection kit plus (lactate dehydrogenase (LDH)) was purchased from Roche. The following primary antibodies were used in these experiments: rabbit anti-Nrf2 (1:200, Santa Cruz Biotechnology), rabbit anti-HO-1 (1:4000, Enzo Life Sciences), rabbit anti- $\beta$-tubulin (1:1000, Cell Signaling Technology), mouse anti-rat CD-3 (1:25, BD Biosciences), rabbit anti-myeloperoxidase (MPO) (1:300, DAKO), mouse anti-CD-68 (1:100, Abcam), and rabbit anti-iNOS (1:80, Abcam).

\section{Primary cortical cultures}

Primary cultures of rat forebrain neurons were used for LIVE/DEAD assay and LDH releasing assay. The cultures were prepared from embryos of Sprague-Dawley rats at day 15 of gestation. The cells were dissociated in dissociation buffer with Papain and DNase I. The cell suspension was passed through a cell strainer and then centrifuged. The pellet was re-suspended in high-glucose DMEM containing $10 \%$ fetal calf serum and plated onto glass coverslips pre-coated with poly-D-lysine in 12-well plates at a final concentration of $2.5 \times 10^{5}$ cells $/ \mathrm{ml}$. At $24 \mathrm{~h}$ after seeding, the medium was changed to Neurobasal medium supplemented with B-27 and Glutamax. The cells were cultured at $37{ }^{\circ} \mathrm{C}$ in a humidified atmosphere of $95 \%$ air and $5 \% \mathrm{CO}_{2}$. Half of the culture medium was replaced with fresh Neurobasal/B27 medium twice a week. The cells were tested after 5-7 days in vitro when most exhibited a neuronal morphology.

Primary mixed neuron/glia cultures of rat cortex were used for real-time PCR (Q-PCR) analysis. The cultures were prepared from embryos of Sprague-Dawley rats at day E15-E17.5 of gestation as described previously $[2,52]$. The cells were plated onto glass coverslips and cultured in DMEM/F12 supplemented with $5 \%$ FBS, $5 \% \mathrm{HS}$ and $1 \% \mathrm{P} / \mathrm{S}(v / v)$ after dissociation (Papain and DNase I) and re-suspension as above. The cells were cultured at $37{ }^{\circ} \mathrm{C}$ in a humidified atmosphere of $95 \%$ air and $5 \% \mathrm{CO}_{2}$. The culture medium was replaced twice per week, and the cells were analyzed by Q-PCR after 7-10 days in vitro. 


\section{Oxygen-glucose deprivation}

MMF was dissolved in DMSO as a $50-\mathrm{mM}$ stock solution and stored in aliquots at $-20{ }^{\circ} \mathrm{C}$. In pretreated groups, the stock solution of MMF was serially diluted in the respective culture medium and cultures were pretreated for $12 \mathrm{~h}$ before OGD. Cell cultures were then washed twice with HBSS and OGD media (glucose and phenol red-free DMEM was deoxygenated by gassing with $95 \%$ nitrogen and $5 \% \mathrm{CO}_{2}$ for $15 \mathrm{~min}$ ) containing either 25, 50, or $100 \mu \mathrm{M}$ MMF. Untreated control cells received DMSO vehicle only. Cultures were then put in a sealed chamber (Billups-Rothenberg, Inc., Del Mar, CA, USA), flushed with $95 \%$ nitrogen and $5 \% \mathrm{CO}_{2}$ for $6 \mathrm{~min}$ at a flow rate of $20 \mathrm{~L} / \mathrm{min}$ and incubated for $1 \mathrm{~h}$ (primary cortical cultures for LIVE/DEAD assay) and $2 \mathrm{~h}$ (mixed neuron/glia cultures for Q-PCR) at $37{ }^{\circ} \mathrm{C}$. The time points were selected based on our empirical data, the literature [2], and MCAO procedure. OGD was terminated by removing the cell culture plates from the chamber, washing, and replacing the glucose-free medium with the respective culture medium with MMF at corresponding concentrations. The cells were then returned to a regular $5 \% \mathrm{CO}_{2}$ incubator. In posttreatment groups, the stock solution of MMF was diluted in the respective culture media and cultures were incubated with MMF after OGD. At 24 and $48 \mathrm{~h}$ after OGD, the media from neuronal culture was collected for LDH assay and cells were processed using the LIVE/DEAD assay to determine cellular viability. At $24 \mathrm{~h}$ after OGD, RNA from mixed cortical culture was extracted for realtime PCR analysis.

\section{LIVE/DEAD assay}

Neuronal viability was quantified using a LIVE/DEAD viability/cytotoxicity kit (Molecular Probes). According to the manufacturer's protocol, coverslips were stained with calcein AM and ethidium homodimer-1, which labeled live cells and dead cells, respectively. Coverslips were then quickly examined under a fluorescence microscope (Olympus IX2-UCB), and pictures were taken. Neuronal death was determined by counting from six random fields per coverslip then averaged and expressed as percentage of cell death (i.e., dead cells/total cells $\times$ $100 \%)$. All assays were repeated in triplicate in three independent experiments.

\section{LDH releasing assay}

Cell injury was quantitatively assessed by measuring lactate dehydrogenase (LDH) in the media, as previously reported [53]. Briefly, cell-free culture medium was collected, and the amount of LDH released into the media was measured by using the Cytotoxicity Detection Kit Plus (Roche) at $24 \mathrm{~h}$ after OGD according to the manufacturer's protocol. Results were read on a Bio-Rad plate reader. Percent cell injury was determined as experimental LDH release/total LDH release after lysis buffer-induced death $\times 100$ after correcting for baseline absorbance. All assays were repeated in triplicate in three independent experiments.

\section{Focal ischemic stroke: MCAO}

Adult male Sprague-Dawley rats weighing 275-300 g were anesthetized, and MCAO was performed as previously reported [54, 55]. For details, adult male SpragueDawley rats weighing 275-300 g were anesthetized using SQ ketamine hydrochloride, xylazine, and acepromazine maleate $(60,10$, and $5 \mathrm{mg} / \mathrm{kg}$, respectively). Body temperature was monitored with a rectal temperature probe and maintained with a heating pad and/or a small fan to within $0.5{ }^{\circ} \mathrm{C}$. Briefly, the right common carotid (CCA) and external and internal carotid arteries (ECA, ICA) were exposed, and the right ECA was ligated. The right CCA was ligated at the proximal end, and the right ICA blood flow was then blocked by clamping using a microclip at its origin. A silicone rubber-coated nylon filament (Doccol) was then inserted into the lumen of the CCA through a small opening. The clamp on the right ICA was then removed, and the nylon filament was carefully advanced into the ICA until it obstructed the middle cerebral artery (MCA). Two hours later, the nylon filament was removed and CCA was ligated to stop bleeding and allow reperfusion of the brain. Mortality rates and poststroke body weight were recorded for all experimental groups. In order to examine the efficiency and tolerance of the DMF in the stroke models and evaluate its effects without bias, no animal was excluded from endpoint analysis unless due to death $(<2 \%)$.

\section{Animal treatment protocol}

Adult male Sprague-Dawley rats weighing 275-300 g were used in these experiments. For behavioral tests, rats were divided into four various control and DMF treatment groups. Treatments were administered by twice daily oral gavage. Group 1 served as normal (Nor) control without MCAO procedure. Group 2 rats were subjected to MCAO and served as control (Veh) for MCAO DMF treatment. Group 3 (dosage $=25 \mathrm{mg} / \mathrm{kg}$ ) and group 4 (dosage $=50 \mathrm{mg} / \mathrm{kg})$ served as DMF treatment groups with oral gavage beginning 2-3 h after MCAO surgery. In groups 3 and 4 , rats received either 25 or $50 \mathrm{mg} / \mathrm{kg}$ of DMF in $0.08 \%$ methocel solution (DMF-treated group) and in group 2, the same amount of methocel solution was used as control. At postoperative $24 \mathrm{~h}, 72-84 \mathrm{~h}$, day 7 , and day 14 , four rats from each group were first evaluated by behavioral tests and then deeply anesthetized. The plasma and brains were collected from some animals in groups 1, 2, and 4 rats for RT-qPCR and Western blot analysis while other animals were transcardially perfused 
with cold $4 \%$ paraformaldehyde for immunocytochemical analysis.

\section{Behavioral tests}

To evaluate neurological function, all rats were subjected to a battery of tests at postoperative $24 \mathrm{~h}, 72-84 \mathrm{~h}$, day 7, and day 14 after MCAO (groups 1-4 above). Motor and sensory deficits were evaluated using a modified neurological severity score (mNSS). Using this scale, one point was given for the inability to perform a test. Consequently, the higher the score, the more severe is the deficit (maximum score $=18$ ). Behavior was assessed at regular intervals by an observer blinded to treatment status.

\section{Evaluation of infarction volume}

Brains were harvested $72 \mathrm{~h}$ after MCAO from control and DMF-treated groups (dosage $=25$ or $50 \mathrm{mg} / \mathrm{kg}$ ). Each brain was sliced into five coronal sections (thickness $=2 \mathrm{~mm}$ ) and then processed for staining with $2 \%$ 2,3,5-triphenyltetrazolium chloride (TTC; Sigma, St. Louis, MO, USA) in saline as described previously. After incubation in $2 \%$ TTC for $20 \mathrm{~min}$ at $37{ }^{\circ} \mathrm{C}$, the brain slices were then fixed in $10 \%$ formalin for $24 \mathrm{~h}$ at room temperature. Infarct volume was measured and calculated by using digital imaging and NIH Image program (Image J software). To control for edema, infarct volume was determined by subtraction of the ipsilateral viable $(\mathrm{TTC}+)$ regional volume from the corresponding contralateral viable $(\mathrm{TTC}+)$ counterpart. This value was then divided by the contralateral value and then multiplied by 100 and expressed as a percent of the contralateral viable volume.

\section{Multiplex cytokine assays}

Plasma was obtained from anticoagulated cardiac blood samples from group 1,2, and 4 rats. The assay was performed using the instructions provided by DartLab (Immunoassay and Flow Cytometry Shared Resource at the Geisel School of Medicine at Dartmouth) as follows. Briefly, cytokines were measured using Millipore rat cytokine multiplex kits (EMD Millipore Corporation, Billerica, MA). Calibration curves from recombinant cytokine standards were prepared with threefold dilution steps in the same matrix as the samples. High and low spikes were included to determine cytokine recovery. Standards and spikes were measured in triplicate, samples were measured in duplicate, and blank values were subtracted from all readings. All assays were carried out directly in a 96-well filtration plate (Millipore, Billerica, MA) at room temperature and protected from light. Briefly, wells were pre-wet with $100 \mu \mathrm{l}$ PBS containing $1 \%$ BSA, and then beads together with a standard, sample, spikes, or blank were added in a final volume of
$100 \mu \mathrm{l}$, and incubated at room temperature for $30 \mathrm{~min}$ with continuous shaking. Beads were then washed three times with $100 \mu \mathrm{l} \mathrm{PBS}$ containing $1 \%$ BSA and $0.05 \%$ Tween 20. A cocktail of biotinylated antibodies $(50 \mu \mathrm{l} /$ well) was added to beads for a further 30-min incubation with continuous shaking. Beads were washed three times, and then streptavidin-PE was added for $10 \mathrm{~min}$. Beads were again washed three times and re-suspended in $125 \mu \mathrm{l}$ of PBS containing $1 \% \mathrm{BSA}$ and $0.05 \%$ Tween 20. The fluorescence intensity of the beads was measured using the Bio-Plex array reader. Bio-Plex Manager software with five-parametric-curve fitting was used for data analysis.

\section{Western blot analysis}

Rats from groups 1, 2 and 4 were briefly perfused transcardially with $0.9 \%$ saline, and the right (ipsilateral) cerebral cortex and striatum (from Bregma 2.5 to $-7.5 \mathrm{~mm}$ ) were dissected and homogenized in lysis buffer containing protease inhibitors. After centrifugation $(17,000 \mathrm{~g}$ for $30 \mathrm{~min}$ ), supernatants were collected and protein concentration was determined. Equal amounts of protein $(20 \mu \mathrm{g})$ were separated by SDS/PAGE (NuPAGE precast polyacrylamide gel) and transferred onto nitrocellulose membrane (Millipore). Membranes were blocked for $1 \mathrm{~h}$ in Tris-buffered saline (TBST), with $0.1 \%$ Tween-20 and $5 \%$ non-fat dry milk, followed by an overnight incubation with primary antibody diluted in the same buffer. Blots were incubated with the appropriate primary antibodies: anti-Nrf2 (1:200), anti-HO-1 (1:4000), or anti$\beta$-III tubulin (1:1000). After washing with TBST, the membrane was incubated with peroxidase-conjugated secondary antibody for $1 \mathrm{~h}$ and then washed and developed using the ECL chemiluminescent detection system. Densitometric analyses were performed using the NIH Image program (ImageJ software), and the ratio between the protein and the corresponding loading control was calculated.

\section{RNA isolation and CDNA synthesis}

In OGD experiments performed in culture, total RNA was isolated directly from primary cortical mixed neuron/glia cultures with TRIzol (invitrogen). Rats from groups 1,2 , and 4 were briefly perfused transcardially with $0.9 \%$ saline, and total RNA was isolated directly from the right (ipsilateral) hemisphere including cerebral cortex and striatum (from Bregma 2.5 to $-7.5 \mathrm{~mm}$ ) with TRIzol. Complementary DNA (cDNA) was synthesized by using $1 \mu \mathrm{g}$ total RNA in a $20 \mu \mathrm{l}$ reaction with Superscript III (invitrogen) and oligo (dT) 18 (invitrogen). One microliter of RNase $\mathrm{H}$ (invitrogen) was added to each reaction tube, and the tubes were incubated for $20 \mathrm{~min}$ at $37^{\circ} \mathrm{C}$ before proceeding to PCR. 
Real-time PCR analysis

Real-time PCR was carried out by 7500 Real-Time PCR System using SYBR green PCR master mix (both from Applied Biosystems). CYPA was used as an internal control. All PCR products were checked by running an agarose gel for the first time and by doing dissociation assay every time to exclude the possibility of multiple products. PCR analyses were conducted in triplicate for each sample. Primers for real-time PCR were designed by using the Primer-BLAST and are listed as Table 1.

\section{Immunostaining/cell quantification}

Animals were perfused with cold $\left(4{ }^{\circ} \mathrm{C}\right)$ paraformaldehyde (4\%). Brains were postfixed in $4 \%$ paraformaldehyde at $4{ }^{\circ} \mathrm{C}$ for $24-36 \mathrm{~h}$, immersed in $30 \%$ sucrose solution at $4{ }^{\circ} \mathrm{C}$, and then embedded in OCT (Tissue-Tek, Sakura, Japan) before cutting with a cryostat (Microm HM505E). Coronal sections were cut at $20 \mu \mathrm{m}$ on a cryostat and collected onto slides. After antigen retrieval, sections were incubated with primary antibodies in blocking buffer containing $0.1 \%$ Triton $\times$ 100 and $5 \%$ normal donkey serum (NDS) in $0.01 \mathrm{M}$ phosphate-buffered saline ( $\mathrm{pH} 7.4)$. Sections were incubated with primary antibodies (anti-MPO, anti-CD3, anti-CD68, and anti-iNOS) for $48 \mathrm{~h}$ at $4{ }^{\circ} \mathrm{C}$, washed, and incubated with secondary antibodies for $2 \mathrm{~h}$ at room temperature in blocking buffer. The nuclear dye DAPI was added after the secondary antibody incubation. Sections were then cover-slipped and examined, and images were acquired using an Olympus IX81 Image Analysis System or laser confocal microscopy (Olympus Fluoview). Sections from similar ischemic brain regions from groups 2 and 4 ( $n=6,5$ sections from each brain) were used for cell quantification. Images of three microscopic fields in the penumbra region of each section were randomly acquired under $\times 100$ magnification and immunopositive cells were counted and expressed as cell number/field.

\section{Statistical analysis}

All data are presented as the mean \pm SEM. The statistical significance of the mean was calculated by the MannWhitney $U$ test or Student's $t$ test. A value of $p<0.05$ was considered significant.

\section{Results}

MMF rescues forebrain neurons from OGD-induced cell death in culture

In a model simulating ischemia in culture, forebrain neurons were isolated from E15 rat embryos and maintained in culture for 7 days before depriving them of oxygen and glucose (OGD) for $1 \mathrm{~h}$. To test the neuroprotective effects of MMF, cultures were treated varying concentrations of MMF $(25-100 \mu \mathrm{M})$, beginning $12 \mathrm{~h}$ prior to OGD and continuing throughout the duration
Table 1 Primer sequences

\begin{tabular}{|c|c|}
\hline Gene & Sequence \\
\hline \multirow[t]{2}{*}{ IL-12A(p35) } & forward 5'-TGTCAATCACGCTACCTCCTC-3' \\
\hline & reverse 5'-AAGACACTTGGCAGGTCCAG-3' \\
\hline \multirow[t]{2}{*}{ IL-12B(p40) } & forward 5'-TGGGAGTACCCTGACTCCTG-3' \\
\hline & reverse 5'-AGGAACGCACCTITCTGGTT-3' \\
\hline \multirow[t]{2}{*}{ IP-10 (CXCL10) } & forward 5'-CCGCATGTTGAGATCATTGCC-3' \\
\hline & reverse 5'-TCTTTGGCTCACCGCTTTCA-3' \\
\hline \multirow[t]{2}{*}{ IFN- $\gamma$} & forward 5'-GCAAAAGGACGGTAACACGA-3' \\
\hline & reverse 5'-TTGCTGATGGCCTGGTTGTC-3' \\
\hline \multirow[t]{2}{*}{ IL-23A(p19) } & forward 5'-GACTAAAAGTGACGTGCCCC-3' \\
\hline & reverse 5'-AAACAGAACTGGCTGTTGTCC-3' \\
\hline \multirow[t]{2}{*}{ IL-18 } & forward 5'-ACCGCAGTAATACGGAGCAT-3' \\
\hline & reverse 5'-TCTGGGATTCGTTGGCTGTT-3' \\
\hline \multirow[t]{2}{*}{$\mid L-1 \beta$} & forward 5'-GGCTTCCTTGTGCAAGTGTC-3' \\
\hline & reverse 5'-AGTCAAGGGCTTGGAAGCAA-3' \\
\hline \multirow[t]{2}{*}{ TNF-a } & forward 5'-ATGGGCTCCCTCTCATCAGT-3' \\
\hline & reverse 5'-GCTTGGTGGTTTGCTACGAC-3' \\
\hline \multirow[t]{2}{*}{ MIP-2 } & forward 5'-CTGAACAAAGGCAAGGCTAACT-3' \\
\hline & reverse 5'-TTGATTCTGCCCGTTGAGGT-3' \\
\hline \multirow[t]{2}{*}{ EOTAXIN } & forward 5'-TTCTATTCCTGCTGCTCACGG-3' \\
\hline & reverse 5'-GTTGGGATGGAACCTGGGTG-3' \\
\hline \multirow[t]{2}{*}{ RANTES (CCL5) } & forward 5'-GTGCCCACGTGAAGGAGTAT-3' \\
\hline & reverse 5'-TCGAGTGACAAAGACGACTGC-3' \\
\hline \multirow[t]{2}{*}{ IL-17 } & forward 5'-ATCCATGTGCCTGATGCTGTT-3' \\
\hline & reverse 5'-AAGTTATTGGCCTCGGCGTT-3' \\
\hline \multirow[t]{2}{*}{ IL-5 } & forward 5'-TGTTGACGAGCAATGAGACGA-3' \\
\hline & reverse 5'-CCCCCTCGGACAGTTTGATT-3' \\
\hline \multirow[t]{2}{*}{ IL-10 } & forward 5'-TGCGACGCTGTCATCGATTT-3' \\
\hline & reverse 5'-TGGCCTTGTAGACACCTITGT-3' \\
\hline \multirow[t]{2}{*}{ GM-CSF } & forward 5'-ATACAAGCAGGGTCTACGGG-3' \\
\hline & reverse 5'-GTCAGTITCCGGGGTTGGA-3' \\
\hline \multirow[t]{2}{*}{ VEGF-A7 } & forward 5'-CACCATGCCAAGTGGTGAAG-3' \\
\hline & reverse 5'-AGATGTCCACCAGGGTCTCA-3' \\
\hline \multirow[t]{2}{*}{ MCP-1 (CCL2) } & forward 5'-TGTCTCAGCCAGATGCAGTTAAT-3' \\
\hline & reverse 5'-TCCAGCCGACTCATTGGGAT-3' \\
\hline \multirow[t]{2}{*}{ CYPA } & forward 5'-TATCTGCACTGCCAAGACTGAGTG-3' \\
\hline & reverse 5'-CTTCTTGCTGGTCTTGCCATTCC-3' \\
\hline \multirow[t]{2}{*}{ GAPDH } & forward 5'-CAACTCCCTCAAGATTGTCAGCAA-3' \\
\hline & reverse 5'-GGCATGGACTGTGGTCATGA-3' \\
\hline
\end{tabular}

of the experiment, and compared to DMSO controls. In posttreatment groups, cultures were incubated with MMF $(25 \mu \mathrm{M})$ or DMSO after $1 \mathrm{~h}$ of OGD. Neuronal survival was then assessed by the LIVE/DEAD assay or by assessing LDH activity in the culture media 24-48 h later. In posttreatment groups, we found fewer dead 
(red) cells at $24 \mathrm{~h}$ in cultures treated with $25 \mu \mathrm{M}$ MMF (28.5 \% in controls vs $21.1 \%$ in MMF treated) (Additional file 1: Figure S1A-C), but there was no significant difference between the two groups when assessed by LDH assay (Additional file 1: Figure S1D). In pretreatment groups, we found significantly fewer dead (red) cells at $24 \mathrm{~h}$ in cultures treated with 25, 50 , or $100 \mu \mathrm{M}$ MMF $(27.4 \%$ in controls vs $13.6 \%$ in $100 \mu \mathrm{M}$ MMF treated) (Fig. 1a-d, i). Similarly, the amount of LDH released into the media by presumptive dead or dying cells was significantly lower in MMF-treated cultures $(21.2 \%$ in controls vs $10.8 \%$ in $100 \mu \mathrm{M}$ MMF treated) (Fig. 1j). Importantly, with continual treatment, MMF-enhanced neuronal rescue was sustained even at later times (48 h post-OGD) $(29.5 \%$ in controls vs $14.0 \%$ in $100 \mu \mathrm{M}$ MMF treated) (Fig. 1e-h, k). Thus, in culture, pretreatment of cells with MMF before OGD was significantly more effective at rescuing dying cells than treatment after OGD.

\section{DMF reduces infarction size and reduces neurobehavioral deficits after MCAO}

To test DMF effects in vivo, rats were administered saline or DMF (25 or $50 \mathrm{mg} / \mathrm{kg}$ ) twice daily via oral gavage, beginning 2-3 $\mathrm{h}$ after $\mathrm{MCAO}$ and continuing until the completion of the experiment. The average weight loss was 30-35 g in the control group and 40-50 g in the DMF-treated group at the 14-day time point. Animals were also subjected to neurobehavioral function tests before and $24 \mathrm{~h}, 72-84 \mathrm{~h}$, and 7 and 14 days after MCAO using a modified neurological severity score (mNSS). Upon sacrifice, the brain was stained with TTC, and infarction volumes were calculated 3 days after MCAO. We found that DMF significantly reduced the size of infarction in TTC-stained sections from $52.2 \%$ in untreated controls at $72 \mathrm{~h}$ after MCAO to $41.8 \%(25 \mathrm{mg} / \mathrm{kg})$ and $29.9 \%(50 \mathrm{mg} / \mathrm{kg})$ in DMF-treated rats (Fig. 2a, b). Correlated with smaller infarction volumes, we observed a significant improvement in neurobehavioral scores (mNSS) in animals administered DMF compared to controls (vehicle treatment) (Fig. 2c). Interestingly, although mNSS scores were nearly identical at the start, by $72 \mathrm{~h}$ after the initiation of either 25 or $50 \mathrm{mg} / \mathrm{kg}$ DMF treatment, scores declined in a dose- and time-dependent manner. Although the greatest behavioral improvement was seen in the first $72 \mathrm{~h}$ after DMF, mNSS scores continued to gradually decline with longer treatment times (up to 14 days, the latest time point examined). These results demonstrate that $25 \mathrm{mg} / \mathrm{kg}$ DMF is less effective than $50 \mathrm{mg} / \mathrm{kg}$ in the MCAO model when neurological behavior test and infarct size (i.e., TTC staining) are assessed. Based on these findings, we used $50 \mathrm{mg} / \mathrm{kg}$ DMF in our subsequent vivo studies.

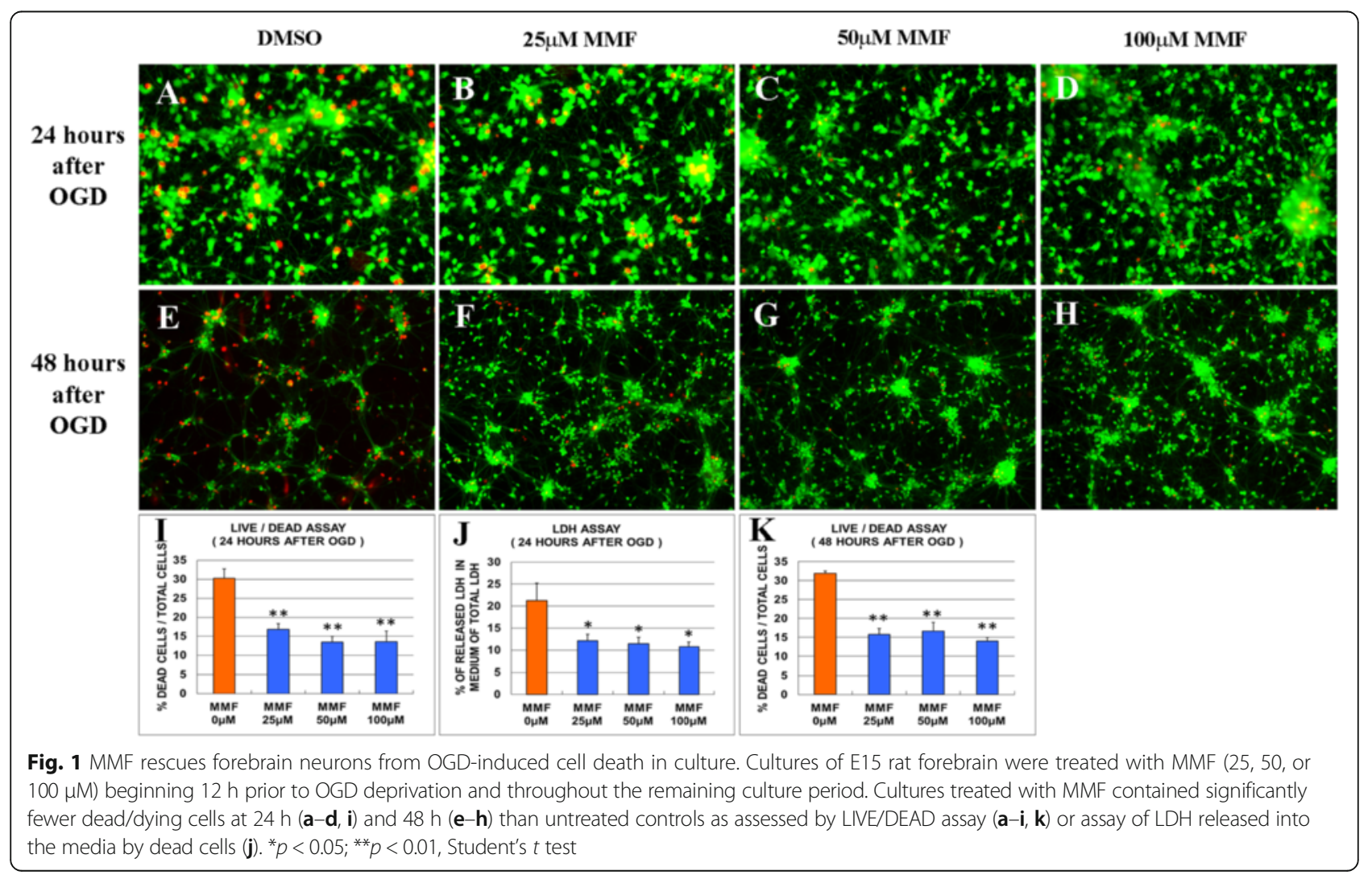




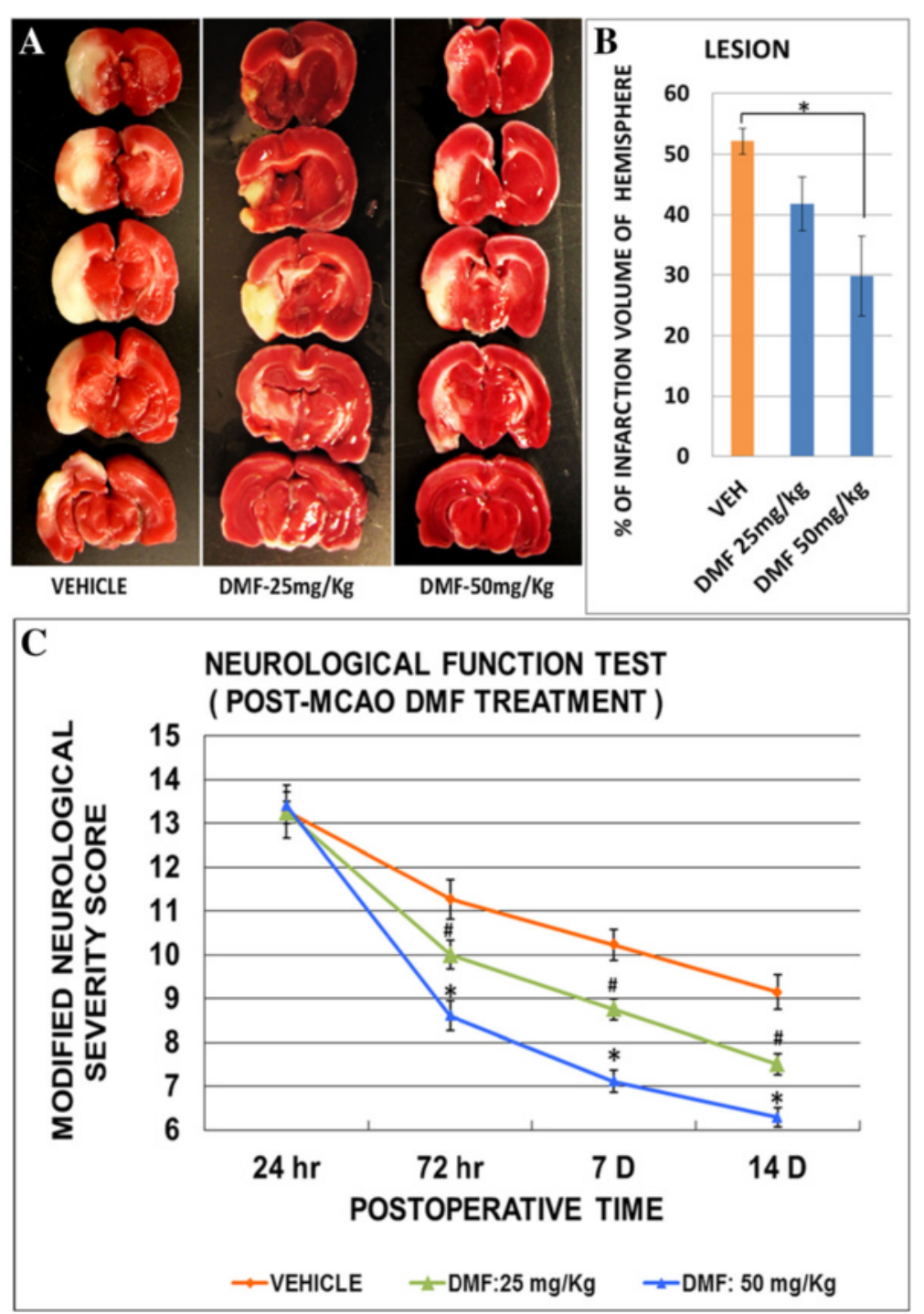

Fig. 2 Infarction size and behavioral assessment after MCAO and DMF treatment. Control (vehicle treated, $n=8)$ and DMF ( 25 or $50 \mathrm{mg} / \mathrm{kg}, n=8$ of each group)-treated rat brains were sectioned and stained for $T T C 72 \mathrm{~h}$ after MCAO (a). Infarction volume was then calculated as described in the "Methods" section using ImageJ and expressed as a percentage of total hemisphere (b). mNSS was assessed at 24 h, 72-84 h, 7 days, or 14 days after MCAO during which rats received either vehicle or 25 or $50 \mathrm{mg} / \mathrm{kg}$ DMF by oral gavage beginning $2-3 \mathrm{~h}$ after MCAO ( $n=8$ of each group). A significant and long-lasting decline in neurobehavioral deficits was seen 72 h, 7 days, and 14 days after the initiation of DMF treatment as compared to controls (c). ${ }^{*},{ }^{*} p<0.05$, Mann-Whitney $U$ test

DMF induces Nrf-2 and its downstream effector HO-1 in the MCAO rat

As DMF (via MMF) is believed to activate Nrf-2, which regulates a host of downstream effector molecules important in limiting oxidant damage, including HO-1 [33, 36-38, 40, 41, 44, 47], we next examined Nrf-2 and HO-1 protein levels in control (vehicle) and DMFtreated MCAO rats and compared levels in the hemisected brain on the side of the injury to normal uninjured hemisphere. We found MCAO itself significantly increased Nrf-2 and HO-1 levels. Importantly, however, DMF treatment markedly increased Nrf-2 levels at $72 \mathrm{~h}$ compared to vehicle-treated controls and normal uninjured brain (Fig. 3a). Although HO-1 levels also increased after DMF treatment, unlike $\mathrm{Nfr}-2$, the rise was not detected until 7 days after the treatment begun (Fig. 3b). While HO-1 remained elevated compared to MCAOvehicle-treated controls at 14 days, levels were decreased from their peak at 7 days (Fig. 3b).

\section{DMF modulates in vitro and in vivo immune factors}

In addition to acting as an antioxidant, DMF is also known to be a potent immunomodulator in a variety of diseases [33-43]. Therefore, we examined immune/ 


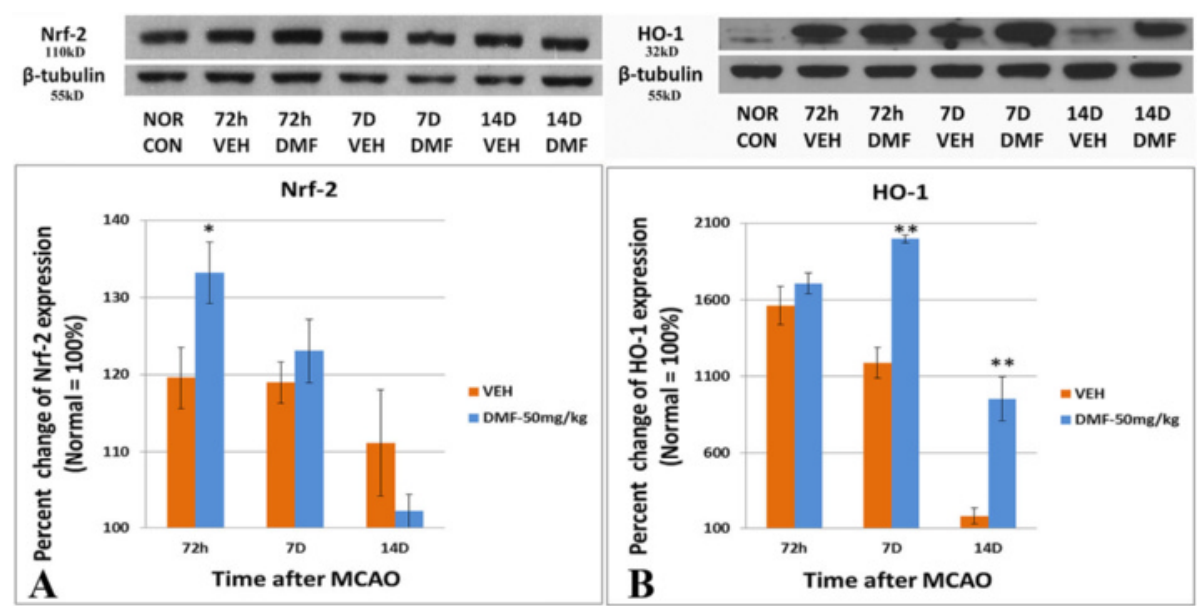

Fig. 3 Western analysis of Nrf-2 and HO-1 after MCAO and DMF treatment. Protein levels of Nrf-2 (a) and HO-1 (b) were measured by Western analysis after vehicle (veh) or $50 \mathrm{mg} / \mathrm{kg}$ DMF treatment for $72 \mathrm{~h}, 7$ days, or 14 days after MCAO ( $n=4$ of each group). All values were expressed as percent change HO-1 expression over normal rat brain (100\%). Significant differences are shown for MCAO/DMF as compared to MCAO/veh. ${ }^{*} p<0.05 ;{ }^{* *} p<0.01$, Mann-Whitney $U$ test

inflammatory cytokines and growth factors in primary mixed neuron/glia cultures and in brain tissue and plasma in MCAO rats after MMF or DMF treatment.

We first examined immune cytokine levels in OGD mixed neuron/glia cultures after treatment with vehicle or MMF using RT-qPCR. IL-12B, IFN- $\gamma$, IL-17, GM-CSF, MIP-2, IL-1 $\beta$, and TNF- $\alpha$ were significantly induced after OGD. In contrast, after incubation with MMF, there was a significant reduction in IL-12B, IFN- $\gamma$, IL-17, GM-CSF, and MIP-2 (Fig. 4a).

We then examined messenger RNA (mRNA) expression levels of immune cytokines and growth factors in the hemisphere ipsilateral to MCAO as compared to the same hemisphere in normal brain in vehicle-treated and DMF-treated rats using Q-PCR. Nearly every factor tested was induced by MCAO alone. However, after 3 days of DMF treatment, a significant decline in IL12p40, IP-10, IL-1 $\beta$, MIP-2, eotaxin, and MCP-1 but surprisingly not IFN- $\gamma$ was observed (Fig. $4 \mathrm{~b}$ ). The decrease in IL-12p40, IP-10, IL-1 $\beta$, MIP-2, and MCP-1 was still observed 14 days after MCAO. Moreover, IL-18 mRNA level started to decrease 7 days after MCAO while IL-17 and IFN- $\gamma$ were decreased by 14 days.

In addition to tissue cytokine levels, on the day of sacrifice, blood was collected (see the "Methods" section) and samples were sent for multiplex analysis of cytokines and growth factors. We found that experimental stroke significantly induced IFN- $\gamma$ levels at $72 \mathrm{~h}$ postMCAO and that the levels remained elevated even at 7 days post-MCAO (Fig. 4c). Importantly, following DMF treatment, IFN- $\gamma$ was significantly decreased at $72 \mathrm{~h}$ when compared to the vehicle-treated MCAO brains or normal brain. In addition, DMF treatment also resulted in a decline in a number of other potentially deleterious inflammatory cytokines, including IL-12p70, IP10, and MCP-1, when compared to vehicle-treated MCAO brain levels. In some cases (IP-10, MCP-1), these early reductions were sustained with continued DMF treatment for 7 days (Fig. 4c). Interestingly, DMF also resulted in a reduction IL-1 $\beta$, IL-17, eotaxin, RANTES, and VEGF levels in plasma at 7 days, even though these factors were unchanged at $72 \mathrm{~h}$ (Fig. 4c). Thus, DMF treatment begun within hours of MCAO and continued thereafter results in both early and late effects on plasma cytokines, causing a profound down-regulation of potentially deleterious inflammatory factors.

\section{DMF reduces immune cell infiltration and microglial activation in the infarct region}

Supporting the notion of DMF-mediated immunomodulation in the brain, we found that the number of MPO+ neutrophils (Fig. 5a-f, m) and CD3+ T cells (Fig. 5g-l, n), which had infiltrated the penumbra region surrounding the infarct, was significantly lower in DMF-treated compared to vehicle-treated (control) MCAO rats.

Additionally, DMF treatment greatly reduced the number of activated CD68+ microglia/macrophages in the penumbra region after MCAO. Thus, in vehicletreated MCAO rats, the number of CD68+ microglia/ macrophages increased dramatically (Fig. 6a-c) compared to normal control rats where relatively few CD68+ cells were observed (data not shown). Importantly, DMF treatment greatly suppressed this inductive effect (Fig. 6d-f), decreasing more than $50 \%$ of CD68+ cells/ microscopic field $(p \leq 0.01)$ at $72 \mathrm{~h}$ (Fig. $6 \mathrm{~g}$ ). The vast majority of CD68+ cells also stained positive with iNOS at $72 \mathrm{~h}$ (Fig. 6h, i, arrows), another marker of activated microglia [18]. 


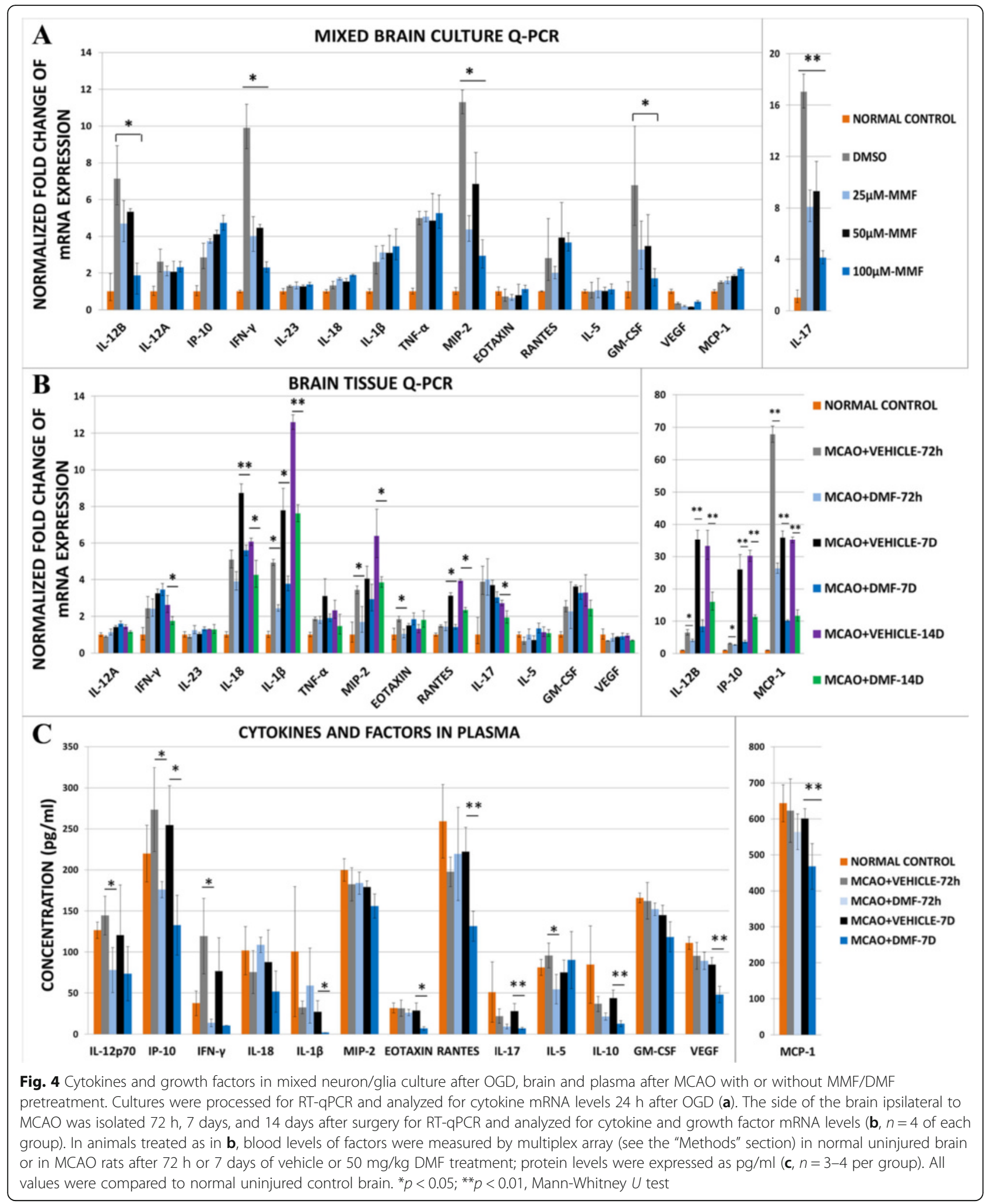

\section{Discussion}

This study demonstrated for the first time that DMF/ MMF has a profound combined antioxidant and anti- inflammatory effect, greatly increasing the short (72 h)and long (7 and 14 days)term rescue of dying and "atrisk" brain neurons in models of ischemic stroke in vivo 


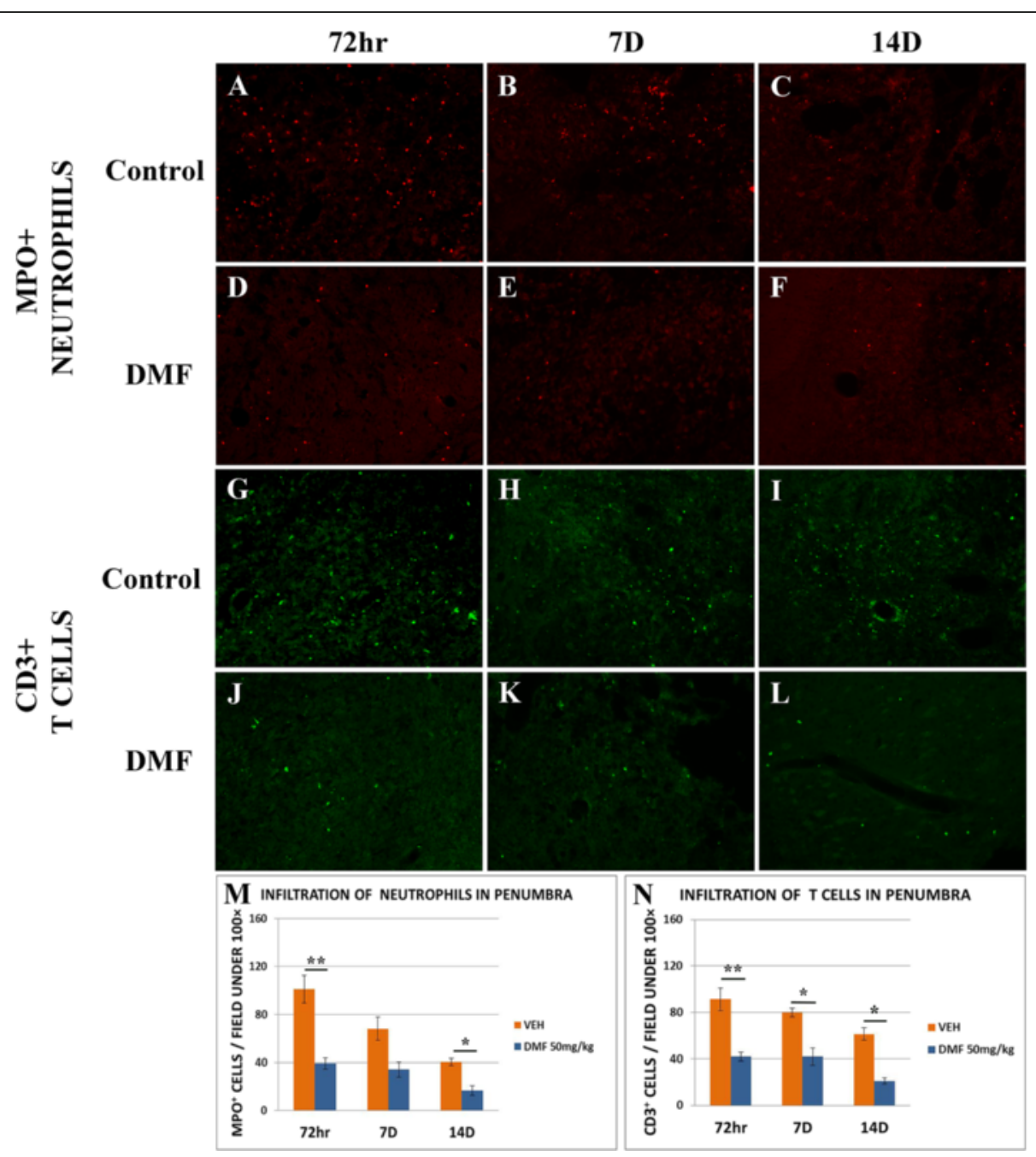

Fig. 5 Analysis of immune cell infiltration into the infarct region 72 h, 7 days, and 14 days after MCAO ( $n=6$ of each group). Neutrophil cells in the infarct region were stained for MPO in control $(\mathbf{a}-\mathbf{c})$ and DMF treated $(\mathbf{d}-\mathbf{f})$ MCAO rats and quantified (M). T cells were stained for CD3 in control $(\mathbf{g}-\mathbf{i})$ and DMF treated $(\mathbf{j}-\mathbf{I})$ MCAO rats and quantified (N). ${ }^{*} p<0.05,{ }^{* *} p<0.01$, Mann-Whitney $U$ test

and in vitro. In cultures, MMF protected cortical neurons from damage and death due to transient oxygenglucose deprivation. This was due in part to the downregulation of potentially deleterious cytokines, consistent with the previous reports [40, 44-46]. In vivo, DMF treatment initiated within several hours of experimental stroke greatly diminished infarction volume and ameliorated behavioral deficits after MCAO. At the molecular level, DMF treatment induced the transcription factor Nrf- 2 and its downstream effector HO-1 in the MCAO brain, both of which are known to be critically important for constraining oxidant damage acutely after stroke [56-59]. Also important and contributing further to the observed beneficial outcome were the long-term changes in the immune landscape of the brain after DMF treatment. Thus, DMF greatly reduced the infiltration of potentially damaging blood immune cells into the infarct, such as $\mathrm{CD} 3+\mathrm{T}$ cells and $\mathrm{MPO}+$ neutrophils, and decreased the levels of harmful inflammatory cytokines in the blood and brain. Furthermore, DMF greatly suppressed the activation of microglia in the penumbra and surrounding brain region.

DMF, which was recently approved by the FDA for the treatment of patients with relapsing-remitting MS [60], has been well characterized previously in animal models of MS [61] and several other neurological disorders $[37,39]$ including hemorrhagic stroke [40, 44] and models of ischemia $[45,46]$. These studies have led to the widespread belief that the molecular basis for the drug's efficacy is the transcription factor Nrf-2 [33, 36, 37, $44,46,47]$ and its regulation of key target genes involved in cellular antioxidant and defense mechanisms [62-64]. Unlike previous studies where analyses were confined to the acute phase (i.e., up to $72 \mathrm{~h}$ after stroke), in the 


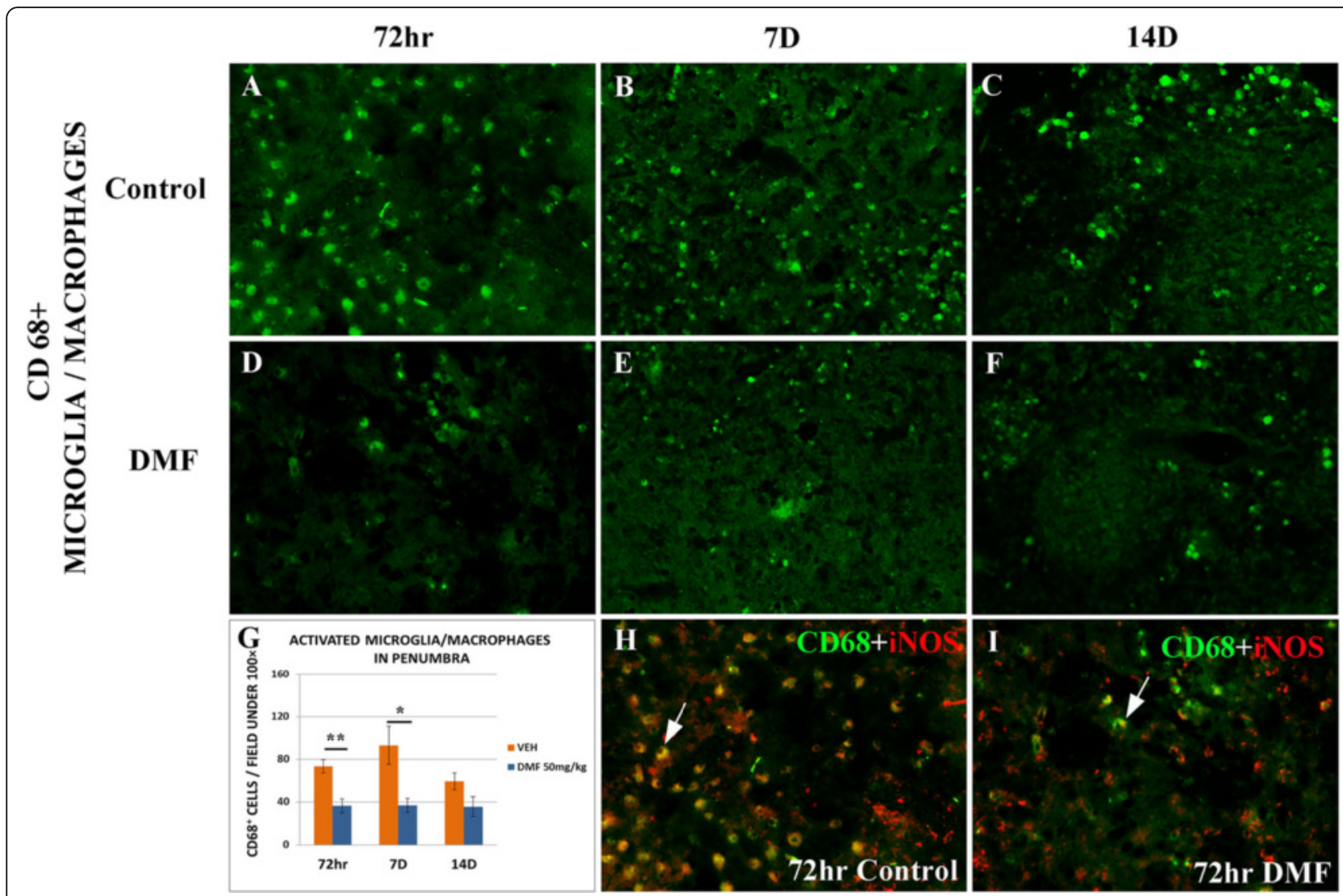

Fig. 6 Analysis of activated microglia/macrophages in penumbra 72 h, 7 days, and 14 days after MCAO ( $n=6$ of each group). Activated microglia/macrophages were stained for CD68 in control $(\mathbf{a}-\mathbf{c})$ and DMF treated $(\mathbf{d}-\mathbf{f})$ MCAO rats, and cell number was quantified (g). iNOS staining was also used to demonstrate activated microglia/macrophages at $72 \mathrm{~h} \mathrm{(h,} \mathbf{i}$, arrows). ${ }^{*} p<0.05,{ }^{* *} p<0.01$, Mann-Whitney U test

present study, neurological behavior along with the brain and blood was analyzed both in the short and long term after DMF treatment.

We found major behavioral improvement in MCAO rats as early as $72 \mathrm{~h}$ after the administration of DMF. Importantly, during this early acute phase in MCAO rats, brain levels of Nrf-2 also increased but interestingly, changes in its crucial downstream mediator HO-1 did not peak until later (7 days after the initiation of treatment), possibly indicating different mechanisms for the early rescue by DMF of dying core cells and the later protection of at-risk penumbra cells.

In particular, the long-term neuroprotective effects of DMF raised the possibility that factors/pathways other than $\mathrm{Nrf}-2 / \mathrm{HO}-1$ and mechanisms other than antioxidant systems might be involved. This contention was further supported by the findings of Zamvil and colleagues showing that Nrf2 does not mediate all activities of fumarates [65]. Since the prolonged harmful consequences of inflammation after stroke are well known $[6,11]$, we examined the immunomodulatory function of DMF in stroke. Indeed, we found that DMF treatment had profound effects on plasma and brain immune cytokines in rats after MCAO as well as in OGD mixed neuron/glia cultures. Of particular note was the dramatic down-regulation in levels of the pro-inflammatory cytokine IFN- $\gamma$ in culture and in plasma.

In addition to IFN- $\gamma$, DMF also significantly reduced the levels of IL-12 in plasma and IL-12p40 in the brain, likely leading to a further down-regulation of IFN- $\gamma$ and its downstream mediator IP-10. Likewise, in OGD mixed neuron/glia cultures, DMF decreased IL-12p40 levels. IL-12, which is produced by activated microglial factors and inhibited by astrocytic factors [49], is known to contribute to inflammatory activity in ischemic stroke. Its suppression has been shown to reduce brain infarct progression after stroke [66], as observed here after DMF treatment.

Additionally, DMF treatment after MCAO resulted in lower levels of many other plasma cytokines including IL-12, IP-10, IL-1 $\beta$, eotaxin, RANTES, IL-17, and MCP-1 at $72 \mathrm{~h}$ and/or 7 days post-infarct. Most of these cytokines/ chemokines are either Th-1 type or pro-inflammatory factors that are normally involved in the activation and subsequent infiltration of peripheral immune cells into the brain and in the activation of resident brain microglial cells 
$[4-7,10-12,15,17,18,20-24,26-28,32,49,67]$. Of particular interest is IL-17A, which is produced primarily by Th17 cells and contributes widely to inflammation and the severity of clinical symptoms in autoimmune diseases like MS and other inflammatory diseases [27, 68, 69]. IL17A promotes the production of inflammatory cytokines and chemokines, leading to the recruitment of IL-17A receptor-expressing immune cells such as neutrophils and macrophages. After stroke and breakdown of the bloodbrain barrier (BBB), there is a massive infiltration of these activated immune cells into the brain, causing secondary brain injury and functional loss. Since DMF/MMF dramatically reduced the levels of IL-17 in plasma from MCAO rats and in OGD mixed cultures, it suggests that IL-17 may play an important role in ischemic stroke, although Th17 cell infiltration and intervention of IL-17 pathway were not directly studied here.

Concomitant with the reduction in these detrimental plasma and brain immune cytokines by DMF, we observed significantly fewer neutrophils and T-lymphocytes infiltrated into the infarct region, further lowering the levels of harmful cytokines in the brain $[8,13-16,19-21,24,25$, 28, 29, 67, 70]. Moreover, we found that DMF decreased activation of brain microglia/macrophages after ischemic stroke, similar to recent reports of the drug's effects in models of hemorrhagic stroke in vitro [47] and in vivo $[40,44]$. Taken together, these findings indicate that DMF acts as a potent immune modulator, down-regulating the further activation of microglia and reducing the infiltration of harmful blood immune cells that could further contribute to brain damage at later times after stroke. These beneficial immunomodulatory effects of DMF, which cannot be adequately explained by the activation of Nrf-2 antioxidant pathway, have been largely underappreciated in stroke. Given the potential clinical utility of the drug, further investigation into the mechanisms involved in DMF immunomodulation is needed.

The unique cytokine profiles in different tissues (i.e., plasma, brain, and nerve/glia cell cultures) elicited by DMF administration could provide valuable information in this regard. For instance, DMF strongly suppresses the IL-12 pathway and down-regulates IFN- $\gamma$ and IP-10 in plasma, while it suppresses IFN- $\gamma$ and IL-17 mRNA level in the mixed cell cultures, indicating a dual role in regulating IL-12 and IL-17 pathways. These could be important for therapeutic target development in the future. Moreover, the differences in tissue-specific cytokine profiles after DMF treatment underscore the importance of linking systemic responses with local brain responses, given the access of circulating peripheral cytokines to the brain after stroke and breakdown of the BBB [54].

Thus, systemically administered DMF may reduce brain inflammation via its direct effects on the peripheral immune system. Conversely however, DMF may also work indirectly to lower brain inflammation. After DMF treatment, there are fewer dying neurons in the brain, less activation of local glia/microglia, and fewer immune cells attracted to the region and likely a reduction in inflammatory cytokines leaking across the damaged BBB to blood, resulting in lower systemic levels of immune cytokines. Thus, DMF may reduce brain inflammation both through direct and indirect mechanisms [45].

In our studies, we observed the early action of DMF after experimental stroke compared to previous reports showing a late effect in MS [71]. There may be several reasons for these differences. In stroke but not MS, the BBB is extensively compromised, allowing rapid efficient access of the brain parenchyma to the drug. Interestingly, DMF was recently shown to improve BBB function after experimental stroke [45]. Also, in MS but not in stroke, infiltrated and activated resident immune cells exist in situ in the brain prior to DMF treatment which could slow the drug's efficacy.

In summary, DMF-induced changes in the immune landscape result in the protection of brain tissue after $\mathrm{MCAO}$, consistent with the observed decrease in infarct volume. As might be expected, the rescue of "at-risk" brain neurons in DMF-treated MCAO rats is correlated with fewer functional deficits and a sharp reduction in mNSS scores early on with a more gradual improvement in behavior over the next several weeks. Possibly, these differences reflect the early actions of DMF on Nrf-2 induction, leading to the rescue of core cells and a smaller infarct in the acute phase. This is followed by later downstream effects on HO-1, the slow rescue of penumbra cells, and a more gradual recovery of behavioral function at later times after stroke which is correlated with a decrease in immune cytokines in the brain and plasma, suggesting an important role for not only local but also the systemic immune system in ameliorating poststroke damage.

\section{Conclusions}

This work shows that DMF, which is already safely used in the clinic to reduce relapse rate and disease progression in MS patients [42, 43], strongly suppresses multiple pro-inflammatory cytokines in in vivo and in vitro stroke models. The improvement of behavioral outcomes is consistent with the observed decrease in infarct volume after MCAO, likely due to the activation of Nrf-2 pathway and the antioxidant effects of DMF.

We conclude that DMF is neuroprotective in experimental stroke because of its dual capacity as an immunomodulatory and antioxidant agent and thus may be useful as a novel therapeutic reagent to treat stroke in patients. As we explore ways to translate this work from bench to bedside, ongoing studies will examine the therapeutic window for DMF efficacy and how we might 
exploit its underlying mechanisms to further impede damaging oxidant (i.e., HO-1) and/or inflammatory signaling pathways (i.e., IL-12 and/or IL-17).

\section{Additional file}

Additional file 1: Figure S1. MMF partially rescues forebrain neurons from OGD-induced cell death in culture. Cultures of E15 rat forebrain were treated with MMF $(25 \mu \mathrm{M})$ beginning after OGD deprivation and throughout the remaining culture period. Cultures treated with MMF contained fewer dead/dying cells at $24 \mathrm{~h}$ than untreated controls as assessed by LIVE/DEAD assay (A-C). No significant difference was observed in assay of $L D H$ released into the media by dead cells $(D)$. ${ }^{*} p<0.05$, Student's $t$ test. (TIF $2483 \mathrm{~kb}$ )

\section{Abbreviations}

DMF: Dimethyl fumarate; GM-CSF: Granulocyte-macrophage colonystimulating factor; HO-1: Heme oxygenase-1; IFNY: Interferon gamma; IP-10: Interferon gamma-induced protein 10; MCAO: Middle cerebral artery occlusion; MCP1: Monocyte chemoattractant protein 1; MIP2: Macrophage inflammatory protein 2; MMF: Monomethylfumarate; mNSS: Modified neurological severity score; MPO: Myeloperoxidase; MS: Multiple sclerosis; Nrf2: (Erythroid-derived 2)-like 2; OGD: Oxygen-glucose deprivation; TNF-a: Tumor necrosis factor-alpha; VEGF: Vascular endothelial growth factor

\section{Acknowledgements}

Thanks to the technical support and data collection of Xiaotao Wei, Cody Nathan, Samuel S. Orr, Justine Zhang, Dr. Matthew C. Havrda, and DartLab (Dartmouth College).

We also gratefully acknowledge the critical discussion with Dr. Mark Curtis, Dr. Guang-Xian Zhang (Thomas Jefferson University), and Dr. Guo-Yuan Yang (Shanghai Jiao Tong University).

\section{Funding}

This research was funded by the Joseph and Marie Field Foundation to RR and $\mathrm{LI}$.

\section{Availability of data and materials}

Data are available on personal demand; please contact author for data requests.

\section{Authors' contributions}

$\mathrm{RL}$ carried out the cell culture, animal experiments, and molecular studies (Q-PCR and Western Blot). JC participated in the cell culture and Q-PCR studies. EK participated in the statistical analysis. LI, RR, and RL conceived of the study, participated in its design, and draft the manuscript. All authors read and approved the final manuscript.

\section{Competing interests}

The authors declare that they have no competing interests.

\section{Consent for publication}

Not applicable.

\section{Ethics approval and consent to participate}

All procedures in this study were carried out in accordance with the recommendations in the Guide for the Care and Use of Laboratory Animals of the National Institutes of Health. The protocol was approved by the IACUC Committee of Thomas Jefferson University.

\section{Disclosures}

None.

\section{Author details}

${ }^{1}$ The Joseph and Marie Field Cerebrovascular Research Laboratory at Jefferson, Vickie \& Jack Farber Institute for Neurosciences, Department of Neuroscience, Sidney Kimmel Medical College, Thomas Jefferson University, 900 Walnut Street, Philadelphia, PA 19107, USA. ${ }^{2}$ The Joseph and Marie Field Cerebrovascular Research Laboratory at Jefferson, Vickie \& Jack Farber
Institute for Neuroscience, Department of Neurological Surgery, Sidney Kimmel Medical College, Thomas Jefferson University, Philadelphia, PA 19107, USA.

Received: 27 April 2016 Accepted: 26 September 2016

Published online: 13 October 2016

\section{References}

1. Global, regional, and national age-sex specific all-cause and cause-specific mortality for 240 causes of death, 1990-2013: a systematic analysis for the Global Burden of Disease Study 2013. Lancet [Internet]. 2014:385:117-71. Available from: http://www.pubmedcentral.nih.gov/articlerender.fcgi?artid= 4340604\&tool=pmcentrez\&rendertype=abstract [cited 2014 Dec 19]

2. Goldberg MP, Choi DW. Combined oxygen and glucose deprivation in cortical cell culture: calcium-dependent and calcium-independent mechanisms of neuronal injury. J Neurosci [Internet]. 1993;13:3510-4. http://www.ncbi.nlm.nih.gov/pubmed/8101871 [cited 2015 Jul 30].

3. Waltz AG. Pathophysiology of cerebral infarction. Clin Neurosurg [Internet]. 1976;23:147-54. http://www.ncbi.nlm.nih.gov/pubmed/824085 [cited 2015 Sep 3]

4. Chapman KZ, Dale VQ, Dénes A, Bennett G, Rothwell NJ, Allan SM, et al. $A$ rapid and transient peripheral inflammatory response precedes brain inflammation after experimental stroke. J Cereb Blood Flow Metab. 2009:29:1764-8.

5. Offner H, Subramanian S, Parker SM, Afentoulis ME, Vandenbark AA, Hurn PD. Experimental stroke induces massive, rapid activation of the peripheral immune system. J Cereb Blood Flow Metab [Internet]. 2006;26:654-65. http://www.ncbi.nlm.nih.gov/pubmed/16121126.

6. Lakhan SE, Kirchgessner A, Hofer M. Inflammatory mechanisms in ischemic stroke: therapeutic approaches. J Transl Med. 2009;7:97.

7. Clausen BH, Lambertsen KL, Babcock A, Holm TH, Dagnaes-Hansen F, Finsen B. Interleukin-1 beta and tumor necrosis factor-alpha are expressed by different subsets of microglia and macrophages after ischemic stroke in mice. J Neuroinflammation. 2008:5:46.

8. Grønberg NV, Johansen FF, Kristiansen U, Hasseldam H. Leukocyte infiltration in experimental stroke. J Neuroinflammation [Internet]. 2013;10:115. http://www.pubmedcentral.nih.gov/articlerender.fcgi?artid= 3852747\&tool=pmcentrez\&rendertype=abstract.

9. Liesz A, Suri-Payer E, Veltkamp C, Doerr H, Sommer C, Rivest S, et al. Regulatory $T$ cells are key cerebroprotective immunomodulators in acute experimental stroke. Nat Med. 2009;15:192-9.

10. Yilmaz G, Arumugam TV, Stokes KY, Granger DN. Role of T lymphocytes and interferon—in ischemic stroke. Circulation. 2006;113:2105-12.

11. ladecola C, Anrather J. The immunology of stroke: from mechanisms to translation. Nat Med [Internet]. 2011;17:796-808. http://www.pubmed central.nih.gov/articlerender.fcgi?artid=3137275\&tool=pmcentrez\& rendertype=abstract [cited 2014 Dec 12].

12. Hurn PD, Subramanian S, Parker SM, Afentoulis ME, Kaler J, Vandenbark A, et al. Reduced lesion size and inflammation. Blood. 2008;27:1798-805.

13. Gelderblom M, Leypoldt F, Steinbach K, Behrens D, Choe CU, Siler D, et al. Temporal and spatial dynamics of cerebral immune cell accumulation in stroke. Stroke. 2009;40:1849-57.

14. Fumagalli S, Perego C, Pischiutta F, Zanier ER, De Simoni M-G. The ischemic environment drives microglia and macrophage function. Front Neurol [Internet]. 2015;6:1-19. Available from: http://journal.frontiersin.org/article/10. 3389/fneur.2015.00081.

15. Kaushal V, Schlichter LC. Mechanisms of microglia-mediated neurotoxicity in a new model of the stroke penumbra. J Neurosci. 2008;28:2221-30.

16. Hanisch U-K, Kettenmann H. Microglia: active sensor and versatile effector cells in the normal and pathologic brain. Nat Neurosci. 2007;10:1387-94.

17. Patel AR, Ritzel R, McCullough LD, Liu F. Microglia and ischemic stroke: a double-edged sword. Int J Physiol Pathophysiol Pharmacol. 2013;5:73-90.

18. Hu X, Li P, Guo Y, Wang H, Leak RK, Chen S, et al. Microglia/macrophage polarization dynamics reveal novel mechanism of injury expansion after focal cerebral ischemia. Stroke. 2012;43:3063-70.

19. Campanella M, Sciorati C, Tarozzo G, Beltramo M. Flow cytometric analysis of inflammatory cells in ischemic rat brain. Stroke. 2002;33:586-92. 
20. Schuette-Nuetgen $K$, Strecker J-K, Minnerup J, Ringelstein EB, Schilling M MCP-1/CCR-2-double-deficiency severely impairs the migration of hematogenous inflammatory cells following transient cerebral ischemia in mice. Exp Neurol [Internet]. 2012;233:849-58. http://www.sciencedirect.com/ science/article/pii/S0014488611004638 [cited 2015 Sep 3].

21. Terao S, Yilmaz G, Stokes KY, Russell J, Ishikawa M, Kawase T, et al. Blood cell-derived RANTES mediates cerebral microvascular dysfunction, inflammation, and tissue injury after focal ischemia-reperfusion. Stroke [Internet]. 2008;39:2560-70. http://www.pubmedcentral.nih.gov/ articlerender.fcgi?artid=2748665\&tool=pmcentrez\&rendertype=abstract [cited 2015 Sep 3].

22. Boutin H, LeFeuvre RA, Horai R, Asano M, Iwakura Y, Rothwell NJ. Role of IL-1alpha and IL-1beta in ischemic brain damage. J Neurosci [Internet]. 2001;21:5528-34. http://www.ncbi.nlm.nih.gov/pubmed/11466424.

23. Lambertsen KL, Gregersen R, Meldgaard M, Clausen BH, Heibøl EK, Ladeby R, et al. A role for interferon-gamma in focal cerebral ischemia in mice. $J$ Neuropathol Exp Neurol [Internet]. 2004;63:942-55. http://www.ncbi.nlm.nih. gov/pubmed/15453093.

24. Strbian D, Karjalainen-Lindsberg M-L, Tatlisumak T, Lindsberg PJ. Cerebral mast cells regulate early ischemic brain swelling and neutrophil accumulation. J Cereb Blood Flow Metab [Internet]. 2006;26:605-12. http://www.ncbi.nlm.nih.gov/pubmed/16163296.

25. Price CJS, Menon DK, Peters AM, Ballinger JR, Barber RW, Balan KK, et al. Cerebral neutrophil recruitment, histology, and outcome in acute ischemic stroke: an imaging-based study. Stroke [Internet]. 2004;35:1659-64. http://www.ncbi.nlm.nih.gov/pubmed/15155970.

26. Rothwell N, Allan S, Toulmond S. The role of interleukin 1 in acute neurodegeneration and stroke: pathophysiological and therapeutic implications. J Clin Invest [Internet]. 1997;100:2648-52. http://www. pubmedcentral.nih.gov/articlerender.fcgi?artid $=508466 \&$ tool $=$ pmcentrez\&rendertype=abstract [cited 2015 Sep 3].

27. Gelderblom M, Weymar A, Bernreuther C, Velden J, Arunachalam P Steinbach $\mathrm{K}$, et al. Neutralization of the IL-17 axis diminishes neutrophil invasion and protects from ischemic stroke. Blood. 2012;120:3793-802.

28. Kim E, Yang JD, Beltran C, Cho S. Role of spleen-derived monocytes/ macrophages in acute ischemic brain injury. J Cereb Blood Flow Metab [Internet]. 2014;07396:1-9. https://www.ncbi.n/m.nih.gov/pubmed/24865998.

29. Buck BH, Liebeskind DS, Saver JL, Bang OY, Yun SW, Starkman S, et al. Early neutrophilia is associated with volume of ischemic tissue in acute stroke. Stroke [Internet]. 2015;39:355-60. http://www.ncbi.nlm.nih.gov/pubmed/ 18162626.

30. Zeng L, Wang Y, Liu J, Wang L, Weng S, Chen K, et al. Pro-inflammatory cytokine network in peripheral inflammation response to cerebral ischemia. Neurosci Lett [Internet]. 2013;548:4-9. http://www.ncbi.nlm.nih.gov/ pubmed/23643982.

31. Fathali N, Ostrowski RP, Hasegawa Y, Lekic T, Tang J, Zhang JH. Splenic immune cells in experimental neonatal hypoxia-ischemia. Transl Stroke Res [Internet]. 2013;4:208-19. http://www.pubmedcentral.nih.gov/articlerender. fcgi?artid=3633221\&tool=pmcentrez\&rendertype=abstract [cited 2015 Sep 14].

32. Zhou P, Qian L, Gallo EF, Deeb RS, Anrather J, Gross SS, et al. The scavenger receptor CD36 contributes to the neurotoxicity of bone marrow-derived monocytes through peroxynitrite production. Neurobiol Dis [Internet]. 2011;42:292-9. http://www.pubmedcentral.nih.gov/articlerender.fcgi?artid= 3079790\&tool=pmcentrez\&rendertype=abstract [cited 2015 Sep 14].

33. Linker R, Lee DH, Ryan S, Van Dam AM, Conrad R, Bista P, et al. Fumaric acid esters exert neuroprotective effects in neuroinflammation via activation of the Nrf2 antioxidant pathway. Brain. 2011;134:678-92.

34. Schilling S, Goelz S, Linker R, Luehder F, Gold R. Fumaric acid esters are effective in chronic experimental autoimmune encephalomyelitis and suppress macrophage infiltration. Clin Exp Immunol. 2006;145:101-7.

35. Moharregh-Khiabani D, Linker R, Gold R, Stangel M. Fumaric acid and its esters: an emerging treatment for multiple sclerosis. Curr Neuropharmacol. 2009;7:60-4.

36. Scannevin $\mathrm{RH}$, Chollate $\mathrm{S}$, Jung MY, Shackett M, Patel H, Bista P, et al. Fumarates promote cytoprotection of central nervous system cells against oxidative stress via the nuclear factor (erythroid-derived 2)-like 2 pathway. J Pharmacol Exp Ther [Internet]. 2012;341:274-84. http://www.ncbi.nlm.nih.gov/ pubmed/22267202\n http://jpet.aspetjournals.org/content/341/1/274.full.pdf.

37. Cross S, Cook DR, Chi AWS, Vance PJ, Kolson LL, Wong BJ, et al. Dimethyl fumarate, an immune modulator and inducer of the antioxidant response, suppresses HIV replication and macrophage-mediated neurotoxicity: a novel candidate for HIV neuroprotection. J Immunol [Internet]. 2011;187:5015-25. http://www.pubmedcentral.nih.gov/articlerender.fcgi?artid=3208057\&tool= pmcentrez\&rendertype =abstract.

38. Wilms H, Sievers J, Rickert U, Rostami-Yazdi M, Mrowietz U, Lucius R. Dimethylfumarate inhibits microglial and astrocytic inflammation by suppressing the synthesis of nitric oxide, IL-1beta, TNF-alpha and IL-6 in an in-vitro model of brain inflammation. J Neuroinflammation. 2010;7:30.

39. Ellrichmann G, Petrasch-Parwez E, Lee DH, Reick C, Arning L, Saft C, et al. Efficacy of fumaric acid esters in the R6/2 and YAC128 models of Huntington's disease. PLoS One. 2011;6:1-11.

40. Zhao X, Sun G, Zhang J, Ting S-M, Gonzales N, Aronowski J. Dimethyl fumarate protects brain from damage produced by intracerebral hemorrhage by mechanism involving Nif2. Stroke [Internet]. 2015;46:1923-928. Available from: http://stroke.ahajournals.org/cgi/doi/10.1161/STROKEAHA.115.009398.

41. Albrecht P, Bouchachia I, Goebels N, Henke N, Hofstetter HH, Issberner A, et al. Effects of dimethyl fumarate on neuroprotection and immunomodulation. J Neuroinflammation [Internet]. 2012;9:163. Available from: ???

42. Killestein J, Rudick RA, Polman $\mathrm{CH}$. Oral treatment for multiple sclerosis. Lancet Neurol [Internet]. 2011;10:1026-34. http://www.ncbi.nlm.nih.gov/ pubmed/22014437.

43. Wingerchuk DM, Carter JL. Multiple sclerosis: current and emerging diseasemodifying therapies and treatment strategies. Mayo Clin Proc [Internet]. 2014;89:225-40. http://www.ncbi.nlm.nih.gov/pubmed/24485135.

44. Iniaghe LO, Krafft PR, Klebe DW, Omogbai EKI, Zhang JH, Tang J. Dimethyl fumarate confers neuroprotection by casein kinase 2 phosphorylation of Nrf2 in murine intracerebral hemorrhage. Neurobiol Dis [Internet]. 2015;82:349. http://linkinghub.elsevier.com/retrieve/pii/S0969996115300061.

45. Kunze R, Urrutia A, Hoffmann A, Liu H, Helluy X, Pham M, et al. Dimethyl fumarate attenuates cerebral edema formation by protecting the blood-brain barrier integrity. Exp Neurol. 2015;266:99-111.

46. Lin-Holderer J, Li L, Gruneberg D, Marti HH, Kunze R. Fumaric acid esters promote neuronal survival upon ischemic stress through activation of the Nif2 but not HIF-1 signaling pathway. Neuropharmacology. 2016;105:228-40.

47. Foresti R, Bains SK, Pitchumony TS, De Castro Brás LE, Drago F, DuboisRandé $J$, et al. Small molecule activators of the Nrf2-HO-1 antioxidant axis modulate heme metabolism and inflammation in BV2 microglia cells. Pharmacol Res [Internet]. 2013;76:132-48. Available from: http://dx.doi.org/10.1016/j.phrs.2013.07.010.

48. Yilmaz G, Arumugam TV, Stokes KY, Granger DN. Role of T lymphocytes and interferon-gamma in ischemic stroke. Circulation [Internet]. 2006;113:2105-12. http://www.ncbi.nlm.nih.gov/pubmed/16636173.

49. Aloisi F, Penna G, Cerase J, Menéndez Iglesias B, Adorini L. IL-12 production by central nervous system microglia is inhibited by astrocytes. J Immunol. 1997:159:1604-12. http://www.jimmunol.org/content/159/4/1604.long.

50. Litjens NHR, Nibbering PH, Barrois AJ, Zomerdijk TPL, Van Den Oudenrijn AC, Noz K, et al. Beneficial effects of fumarate therapy in psoriasis vulgaris patients coincide with downregulation of type 1 cytokines. Br J Dermatol. 2003;148:444-51.

51. Moed H, Stoof TJ, Boorsma DM, Von Blomberg BME, Gibbs S, Bruynzeel DP, et al. Identification of anti-inflammatory drugs according to their capacity to suppress type-1 and type-2 T cell profiles. Clin Exp Allergy. 2004;34:1868-75.

52. Ovanesov MV, Ayhan Y, Wolbert C, Moldovan K, Sauder C, Pletnikov MV. Astrocytes play a key role in activation of microglia by persistent Borna disease virus infection. J Neuroinflammation [Internet]. 2008;5:50. http://www.ncbi.nlm.nih.gov/pubmed/19014432

53. Koh JY, Choi DW. Quantitative determination of glutamate mediated cortical neuronal injury in cell culture by lactate dehydrogenase efflux assay. J Neurosci Methods [Internet]. 1987;20:83-90. http://www.ncbi.nlm.nih.gov/ pubmed/2884353.

54. Lin R, Cai J, Nathan C, Wei X, Schleidt S, Rosenwasser R, et al. Neurogenesis is enhanced by stroke in multiple new stem cell niches along the ventricular system at sites of high BBB permeability. Neurobiol Dis [Internet]. 2015;74:229-39. http://www.ncbi.nlm.nih.gov/pubmed/25484283.

55. Goldmacher GV, Nasser R, Lee DY, Yigit S, Rosenwasser R, lacovitti L. Tracking transplanted bone marrow stem cells and their effects in the rat MCAO stroke model. PLoS One [Internet]. 2013;8:e60049. http://www.pubmedcentral.nih.gov/articlerender.fcgi?artid=3612030\&tool= pmcentrez\&rendertype=abstract [cited 2015 May 15].

56. Zhang M, Wang S, Mao L, Leak RK, Shi Y, Zhang W, et al. Omega-3 fatty acids protect the brain against ischemic injury by activating Nrf2 and upregulating heme oxygenase 1. J Neurosci [Internet]. 2014;34:1903-15. 
http://www.pubmedcentral.nih.gov/articlerender.fcgi?artid=3905150\&tool= pmcentrez\&rendertype=abstract [cited 2015 Jun 17].

57. Shih AY, Li P, Murphy TH. A small-molecule-inducible Nrf2-mediated antioxidant response provides effective prophylaxis against cerebral ischemia in vivo. J Neurosci. 2005;25:10321-35.

58. Panahian N, Yoshiura M, Maines MD. Overexpression of heme oxygenase-1 is neuroprotective in a model of permanent middle cerebral artery occlusion in transgenic mice. J Neurochem [Internet]. 1999;72:1187-203. http://www.ncbi.nlm.nih.gov/pubmed/10037492.

59. Zhang F, Wang S, Zhang M, Weng Z, Li P, Gan Y, et al. Pharmacological induction of heme oxygenase-1 by a triterpenoid protects neurons against ischemic injury. Stroke [Internet]. 2012;43:1390-7. http://www. pubmedcentral.nih.gov/articlerender.fcgi?artid=3335928\&tool= pmcentrez\&rendertype=abstract [cited 2015 Jul 30].

60. Gold R, Kappos L, Arnold DL, Bar-Or A, Giovannoni G, Selmaj K, et al. Placebo-controlled phase 3 study of oral BG-12 for relapsing multiple sclerosis. N Engl J Med [Internet]. 2012;367:1098-107. http://www.ncbi.nlm. nih.gov/pubmed/22992073.

61. Chen H, Assmann JC, Krenz A, Rahman M, Grimm M, Karsten CM, et al. Hydroxycarboxylic acid receptor 2 mediates dimethyl fumarate's protective effect in EAE. J Clin Invest [Internet]. 2014;124:2188-92. http://www. pubmedcentral.nih.gov/articlerender.fcgi?artid $=4001545 \&$ tool $=$ pmcentrez\&rendertype=abstract [cited 2015 Jul 30].

62. Zhao J, Moore AN, Redell JB, Dash PK. Enhancing expression of Nrf2-driven genes protects the blood brain barrier after brain injury. J Neurosci [Internet]. 2007:27:10240-8. http://www.ncbi.nlm.nih.gov/pubmed/17881530

63. Moi P, Chan K, Asunis I, Cao A, Kan YW. Isolation of NF-E2-related factor 2 (Nrf2), a NF-E2-like basic leucine zipper transcriptional activator that binds to the tandem NF-E2/AP1 repeat of the beta-globin locus control region. Proc Natl Acad Sci U S A [Internet]. 1994;91:9926-30. http://www.pubmedcentral. nih.gov/articlerender.fcgi?artid=44930\&tool=pmcentrez\&rendertype=abstract [cited 2015 Sep 2].

64. Kaspar JW, Niture SK, Jaiswal AK. Nrf2:INrf2 (Keap1) signaling in oxidative stress. Free Radic Biol Med [Internet]. 2009;47:1304-9. http://www. sciencedirect.com/science/article/pii/S0891584909004699 [cited 2015 Sep 2]

65. Schulze-Topphoff U, Varrin-Doyer M, Pekarek K, Spencer CM, Shetty A, Sagan $S A$, et al. Dimethyl fumarate treatment induces adaptive and innate immune modulation independent of Nrf2. Proc Natl Acad Sci U S A [Internet]. 2016;113:4777-82. http://www.ncbi.nlm.nih.gov/pubmed/ 27078105.

66. Zaremba J, Losy J. Interleukin-12 in acute ischemic stroke patients. Folia Neuropathol. 2006;44:59-66.

67. Hao Q, Chen Y, Zhu Y, Fan Y, Palmer D, Su H, et al. Neutrophil depletion decreases VEGF-induced focal angiogenesis in the mature mouse brain. J Cereb Blood Flow Metab [Internet]. 2007;27:1853-60. http://www.ncbi.nIm. nih.gov/pubmed/17392691.

68. Ciric B, El-behi M, Cabrera R, Zhang GX, Rostami A. IL-23 drives pathogenic IL-17-producing CD8+ T cells. J Immunol. 2009;182:5296-305.

69. Hueber W, Patel DD, Dryja T, Wright AM, Koroleva I, Bruin G, et al. Effects of AIN457, a fully human antibody to interleukin-17A, on psoriasis, rheumatoid arthritis, and uveitis. Sci Transl Med [Internet]. 2010;2:52ra72. http://www. ncbi.nlm.nih.gov/pubmed/20926833.

70. DeFrancesco-Lisowitz a., Lindborg J a., Niemi JP, Zigmond RE. The neuroimmunology of degeneration and regeneration in the peripheral nervous system. Neuroscience [Internet]. IBRO; 2014. Available from: http://linkinghub.elsevier.com/retrieve/pii/S0306452214007696.

71. Kappos L, Giovannoni G, Gold R, Phillips JT, Arnold DL, Hotermans C, et al. Time course of clinical and neuroradiological effects of delayed-release dimethyl fumarate in multiple sclerosis. Eur J Neurol [Internet]. 2015;22:664-71. http://www.ncbi.nlm.nih.gov/pubmed/25557371.

\section{Submit your next manuscript to BioMed Central and we will help you at every step:}

- We accept pre-submission inquiries

- Our selector tool helps you to find the most relevant journal

- We provide round the clock customer support

- Convenient online submission

- Thorough peer review

- Inclusion in PubMed and all major indexing services

- Maximum visibility for your research

Submit your manuscript at www.biomedcentral.com/submit
Biomed Central 